\title{
ИЗУЧЕНИЕ ДИЭЛЕКТРИЧЕСКИХ СВОЙСТВ ПОЛИМЕРНЫХ МАТЕРИАЛОВ НА ОСНОВЕ ПРОИЗВОДНЫХ БЕНЗОЦИКЛОБУТЕНА
}

\author{
С.Е. Балаченкова, Г.Е. Адамов, К.С. Левченко, А.Ю. Калашников, \\ П.С. Шмелин, Е.П. Гребенников
}

\begin{abstract}
СВЕТЛАНА ЕВГЕНЬЕВНА БАЛАЧЕНКОВА - студент 4 курса Института тонких химических технологий им. М.В. Ломоносова РТУ МИРЭА. E-mail: balachenkova.sveta@yandex.ru.
\end{abstract}

ГРИГОРИЙ ЕВГЕНЬЕВИЧ АДАМОВ - к.т.н., начальник лаборатории АО «ЦНИТИ «Техномаш».

E-mail:adamov@cnititm.ru.

КОНСТАНТИН СЕРГЕЕВИЧ ЛЕВЧЕНКО - к.х.н., младший научный сотрудник института синтетических полимерных материалов им. Н.С.Ениколопова РAH.E-mail: k.s.levchenko@gmail.com.

АНТОН ЮРЬЕВИЧ КАЛАШНИКОВ - ведущчий инженер-технолог АО «Российские космические системы». E-mail:kalashton@inbox.ru.

ПАВЕЛ СЕРГЕЕВИЧ ШМЕЛИН - начальник отдела АО «ЦНИТИ «Техномаш».E-mail: shmelin@cnititm.ru. ЕВГЕНИЙ ПЕТРОВИЧ ГРЕБЕННИКОВ - д.т.н., директор по науке АО «ЦНИТИ «Техномаш».

E-mail: grebennikov@cnititm.ru.

119571, г. Москва, пр-кт Вернадского, 86, Федеральное государственное бюджетное образовательное учреждение высшего образования «МИРЭА - Российский технологический университет».

121108, г. Москва, ул. Ивана Франко, 4, Акционерное общество «Центральный научно-исследовательский технологический институт «Техномаш».

117393, г. Москва, ул. Профсоюзная, 70, Институт Синтетических Полимерных Материалов им. Н.С. Ениколопова РАН.

111250, г. Москва, ул. Авиамоторная, 53, Акциионерное общество «Российские космические системы»».

В рамках статьи исследованы диэлектрические характеристики полимерных пленок двух аллил-замещенных производных силанов с бензоциклобутеновым заместителем и их сополимеров с диметакрилатом триэтиленгликоля, введение которого придавало материалам способность к фотополимеризаиии. Полученные значения диэлектрической пронииаемости (менее 2,9 на частоте 10 ГГи) и тангенса угла потерь (менее $3 \cdot 10^{-3}$ на частоте 10 ГГи) делают разработанные материалы перспективными для применения в качестве диэлектрических покрытий в технологических процессах формирования компонентов электронных устройств.

Ключевые слова: производные бензоциклобутена, диэлектрическая проницаемость, тангенс угла потерь. 


\title{
DIELECTRIC PROPERTIES OF POLYMERIC MATERIALS BASED ON BENZOCYCLOBUTENE DERIVATIVES
}

\author{
S.E. Balachenkova ${ }^{1}$, G. E. Adamov ${ }^{2}$, K. S. Levchenko ${ }^{3}$, A.Yu. Kalashnikov ${ }^{4}$, \\ P.S. Shmelin ${ }^{2}$, E. P. Grebennikov ${ }^{2}$
}

186, Vernadsky Avenue, Moscow, 119571, Russia, RTU MIREA - Russian Technological University.

24, Ivana Franko Str., Moscow, 121108, Russia, JSC «Technomash».

370, Profsoyuznaya Str., Moscow, 117393, Russia, Enikolopov Institute of Synthetic Polymeric Materials of the Russian Academy of Sciences, Moscow, Russia.

453, Aviamotornaya Str., Moscow, 111250, Russia, JSC “Russian space systems”.

In this article the dielectric characteristics of polymer films based on two allyl-substituted silanes with a benzocyclobutene substituent and their copolymers with triethylene glycol dimethacrylate at a frequencies of 1 and $10 \mathrm{GHz}$ were studied. The obtained values of the dielectric constant (less than 2,9 at a frequency of $10 \mathrm{GHz}$ ) and the loss tangent (less than $3 \cdot 10^{-3}$ at a frequency of $10 \mathrm{GHz}$ ) make the developed materials promising for use as dielectric coatings in microelectronics.

Keywords: benzocyclobutene derivatives, dielectric constant, loss tangent.

Полимерные материалы на основе бензоциклобутена (БЦБ) нашли широкое применение в современной микроэлектронике. Термореактивные материалы на основе БЦБ показывают характеристики, благодаря которым они имеют множество преимуществ перед другими известными материалами на основе полиакрилатов, полиимидов, эпоксидных смол, фенолформальдегидных композиций и других.

Среди таких свойств:

1) низкое значение диэлектрической проницаемости $(\varepsilon \leq 2,9)$ и тангенса угла диэлектрических потерь $(\operatorname{tg} \leq 0,008)$;

2) высокая устойчивость к химическим воздействиям;

3) высокая стабильность при температурах 300$450{ }^{\circ} \mathrm{C}$;

4) хорошая адгезия к металлам;

5) низкая температура отверждения (как правило, от 150 до $250{ }^{\circ} \mathrm{C}$ ) и умеренная (менее $5 \%$ ) усадка в ходе этого процесса;

6) высокая степень выравнивания поверхности;

7) устойчивость к влаге (накапливают менее 0,14-1,00 \% воды при длительном выдерживании во влажной атмосфере при высоких температурах) [1, 2].

Также особенностью химических превращений материалов на основе бензоциклобутена в ходе по- лимеризации является отсутствие катализаторов, инициаторов и различных газообразных побочных продуктов [3]. Такой набор свойств обуславливает высокую востребованность материалов на основе БЦБ в технологических цепочках изготовления различных устройств микроэлектроники [4].

Ключевыми функциональными характеристиками материалов на основе бензоциклобутена являются значения диэлектрической проницаемости и тангенса угла диэлектрических потерь. В работе представлены исследования диэлектрических характеристик на частотах 1 ГГц и 10 ГГц полимерных материалов на основе синтезированных авторами производных БЦБ $[5,6]$ и их сополимеров с диметакрилатом триэтиленгликоля (ТГМ-3). Введение в композитный состав ТГМ-3 придавало материалам способность к фотополимеризации, что повышает технологичность исследованных композиций.

На рисунке 1 приведены структурные формулы производных бензоциклобутена: 1,3-диаллил-1,3-ди[бицикло[4.2.0]окта-1,3,5-триен3-ил]-1,3-диметил силоксана (БЦБ-КА) и аллилбис(бензоциклобутен-3-ил)-метил силана (БЦБДКА), полимерные материалы на основе которых исследованы в рамках данной работы.

Получение пленок из 100 \% производных БЦБ осуществлялось методом термополимеризации 

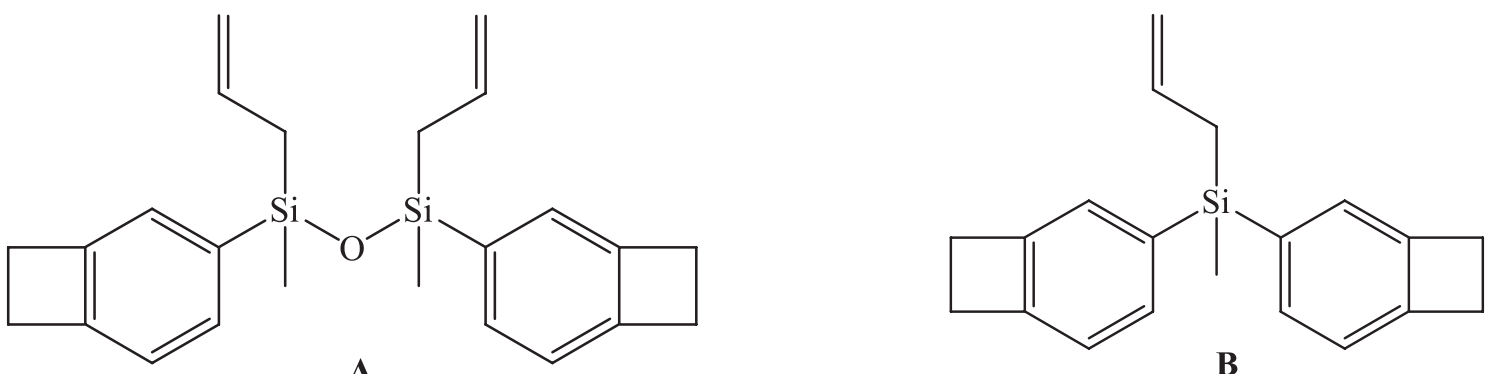

Рис. 1. Структурные формулы исследованных производных бензоциклобутена

А - 1,3-диаллил-1,3-ди[бицикло[4.2.0]окта-1,3,5-триен-3-ил]-1,3-диметил силоксан (БЦБ-КА);

В - аллил-бис(бензочиклобутен-3-ил)-метил силан (БЦБ-ДКА)

при $200{ }^{\circ} \mathrm{C}$ в течение 2 часов в инертной атмосфере аргона.

Формирование пленок из композиционных составов, содержащих соответствующее производное БЦБ и ТГМ-3, осуществлялось в две стадии.

На первой, за счет фотополимеризации, формировался каркас из полимерного ТГМ-3. Для проведения фотоотверждения в систему добавляли фотоинициатор Darocur 4265 в количестве $3 \%$ (вес.). Процесс полимеризации проводился под воздействием осветителя на основе светодиодных источников света с максимумом длины волны 395 нм в течение 1 часа.

На второй стадии осуществлялось сшивание за счет термореактивного БЦБ-фрагмента в ходе термообработки при $200{ }^{\circ} \mathrm{C}$ в течение 2 часов в инертной атмосфере аргона.

Измерения диэлектрических параметров в диапазоне частот 1 МГц-1 ГГц проводились на анализаторе импеданса и параметров материалов Agilent E4991A Material Analyzer с использованием измерительной оснастки Agilent 16453A.

Начальная калибровка прибора проводилась при помощи последовательной установки калибровочных сопротивлений (Open, Short, Load 50 Ohm) из калибровочного набора Agilent Calibration Kit $7 \mathrm{~mm}$

Калибровка оснастки осуществлялась при помощи калибровочного образца из политетрафторэтилена толщиной 750 мкм и диэлектрической проницаемостью $\varepsilon=2,1$. Результаты измерений обрабатывались при помощи программного обеспечения прибора.

В таблице 1 приведены результаты исследования диэлектрических характеристик полимерных пленок различных композиционных составов, полученных в рамках данной работы.

Измерение диэлектрических характеристик на частоте 10 ГГц проводилось методом объемного
Таблиияа 1

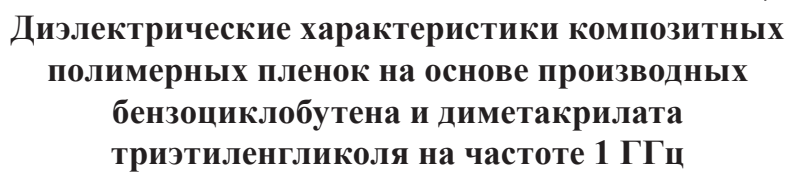

\begin{tabular}{clcc}
\hline № & Состав полимера & $\boldsymbol{\varepsilon}\left(\mathbf{T}=\mathbf{2 5}{ }^{\circ} \mathbf{C}\right)$ & $\boldsymbol{t g}\left(\mathbf{T}=\mathbf{2 5}{ }^{\circ} \mathbf{C}\right)$ \\
\hline 1 & БЦБ-КА & 2,909 & $1,54 \cdot 10^{-3}$ \\
2 & БЦБ-КА/ТГМ-3 (75/25) & 3,084 & $16,10 \cdot 10^{-3}$ \\
3 & БЦБ-КА/ТГМ-3 (50/50) & 3,172 & $18,31 \cdot 10^{-3}$ \\
4 & БЦБ-КА/ТГМ-3 (25/75) & 3,530 & $31,47 \cdot 10^{-3}$ \\
5 & БЦБ-ДКА & 2,757 & $1,53 \cdot 10^{-3}$ \\
6 & БЦБ-ДКА/ТГМ-3 (50/50) & 3,181 & $19,32 \cdot 10^{-3}$ \\
7 & БЦБ-ДКА/ТГМ-3 (25/75) & 3,297 & $28,40 \cdot 10^{-3}$ \\
\hline
\end{tabular}

резонанса при фиксированной резонансной частоте по ГОСТ 8.623-2006.

Для этого был использован измерительный стенд, включающий в себя ВЧ Генератор Г 4-83, Резонатор ДК 565, Измеритель отношения напряжения В8-7 и Осциллограф C1-76. Для измерений применялся цилиндрический объемный резонатор, в котором возбуждается колебание типа $\mathrm{H}_{01 \mathrm{p}}$, где $p$ - число полуволн, укладывающихся по длине резонатора. Внутренний диаметр резонатора 50 мм, длина резонансной полости 80 мм.

Определение относительной диэлектрической проницаемости $\varepsilon$ заключалось в измерении разности резонансной длины резонатора без образца и резонансной длины после помещения в него образца при фиксированной резонансной частоте.

Определение тангенса угла диэлектрических потерь $t g$ заключалось в измерении собственной добротности резонатора с образцом и сравнении ее с собственной добротностью резонатора без образца с учетом изменения распределения поля и омических потерь в стенках резонатора после помещения образца. 
В таблице 2 представлены результаты исследования диэлектрических характеристик полимерных пленок различных композиционных составов, полученных в рамках данной работы на частоте 10 ГГц.

Таблица 2

Диэлектрические характеристики композитных полимерных пленок на основе производных бензоциклобутена и диметакрилата триэтиленгликоля на частоте 10 ГГц

\begin{tabular}{clcc}
\hline № & Состав полимера & $\boldsymbol{\varepsilon}\left(\mathbf{T}=\mathbf{2 5} \mathbf{C}^{\circ} \mathbf{~}\right.$ & $\left.\boldsymbol{t} \boldsymbol{( \mathbf { T } = \mathbf { 2 5 }}{ }^{\circ} \mathbf{C}\right)$ \\
\hline 1 & БЦБ-КА & 2,343 & $4,43 \cdot 10^{-4}$ \\
2 & БЦБ-КА/ТГМ-3 (75/25) & 2,481 & $1,21 \cdot 10^{-3}$ \\
3 & БЦБ-КА/ТГМ-3 (50/50) & 2,531 & $1,78 \cdot 10^{-3}$ \\
4 & БЦБ-КА/ТГМ-3 (25/75) & 2,766 & $2,94 \cdot 10^{-3}$ \\
5 & БЦБ-ДКА & 2,687 & $3,71 \cdot 10^{-4}$ \\
6 & БЦБ-ДКА/ТГМ-3 (50/50) & 2,813 & $1,30 \cdot 10^{-3}$ \\
7 & БЦБ-ДКА/ТГМ-3 (25/75) & 2,862 & $2,65 \cdot 10^{-3}$ \\
\hline
\end{tabular}

Гомополимеры на основе синтезированных производных БЦБ демонстрируют показатели диэлектрической проницаемости, сравнимые с известными аналогами от компании Dow Chemicals, выпускаемые под маркой Cyclotene ${ }^{\mathrm{TM}}$ [7]. Это делает синтезированные производные перспективными для дальнейшего использования при получении диэлектрических покрытий в технологических процессах формирования компонентов электронных устройств.

Композиционные материалы, включающие БЦБ-содержащие молекулы и метакрилатное производное ТГМ-3, являются способными к фотополимеризации, что расширяет их технологические возможности за счет использования методов фотолитографии.

Введение в композиционный состав ТГМ-3 приводит к некоторому увеличению значения диэлектрической проницаемости и тангенса угла потерь по сравнению с гомополимером, которое тем больше, чем больше содержание ТГМ-3. Следует отметить, что зависимость диэлектрических параметров от состава более заметно проявляется на частоте 1 ГГц, тогда как на частоте 10 ГГц она менее выражена. При этом для полимерных компо- зиционных материалов на основе БЦБ-КА наблюдается большее изменение значений диэлектрических параметров на разных частотах по сравнению с материалами на основе БЦБ-ДКА.

В целом, можно констатировать, что гомополимеры на основе БЦБ-КА и БЦБ-ДКА демонстрируют показатели диэлектрической проницаемости, сравнимые с аналогами марки Cyclotene ${ }^{\mathrm{TM}}-$ коммерчески доступными материалами, применяемыми в микроэлектронной промышленности. При этом, введение в состав смеси метакрилатного производного ТГМ-3, являющегося способным к фотополимеризации, расширяет технологические возможности исследуемых материалов за счет возможности применения методов фотолитографии для формирования полимерных слоев. Это делает исследуемые материалы перспективными для использования при получении диэлектрических покрытий в технологических процессах формирования компонентов электронных устройств.

Работа выполнена при поддержке Министерства науки и выстего образования Российской федераиии. Согламение о предоставлении из федерального бюджета грантов в форме субсидий от 22 ноября 2019 года № 075-15-2019-1694 (внутренний номер Согламения 05.604.21.0227), уникальный идентификатор RFMEFI60419X0227.

\section{Литература}

1. Левченко К.С., Чудов К.А., Адамов Г.Е., Порошин Н.О., Шмелин П.С., Гребенников Е.П., Паршиков Ю.Г. Российский химический журнал. 2016. T. LX. № 4. C. 47-63.

2. Zhao X.-Y., Liu H.-J. Polymer International. 2010. V. 59. I. 5. P. 597-606.

3. Cao K., Yang L., Huang Y., Chang G., Yang J. Polymer. 2014. V. 55. №. 22. P. 5680-5688.

4. URL: https://en.wikipedia.org/wiki/Benzocyclobutene

5. Levchenko K.S., Adamov E.G., Demin D.U., Chudov K.A., Bulanova A.V., Lyssenko K.A., Kalashnikov A.Yu., Shmelin P.S., Grebennikov E.P. Journal of Physics: Conference Series. 2019. V. 1347. P. 012030

6. Levchenko K.S. et al. New crosslinking monomer based on benzocyclobutene for microelectronics // in press.

7. Mills M.E., Townsend P., Castillo D., Martin S., Achen A. Microelectronic Engineering. 1997. V. 33. I. 1-4. P. 327-334. 